\title{
Diagnosing and Treating Food Allergy
}

\author{
Roberto Berni Canani - Rita Nocerino - Vincenza Pezzella $\cdot$ Ludovica Leone \\ Tommaso Cozzolino - Rosita Aitoro • Lorella Paparo - Margherita Di Costanzo • \\ Linda Cosenza $\cdot$ Riccardo Troncone
}

Published online: 4 August 2013

(C) Springer Science + Business Media New York 2013

\begin{abstract}
Food allergy (FA) is defined as an abnormal immunological reaction to food proteins. Over $90 \%$ of FAs in childhood are caused by eight foods: cow's milk, hen's egg, soy, peanuts, tree nuts, wheat, fish and shellfish. The diagnostic work up for a child with suspected FA includes detailed medical history, physical examination, FA screening tests and response to elimination diet and to oral food challenge. Sometimes additional diagnostic tools to explore intestinal damage and function could be adopted. Currently, the only treatment for FA relies on strict elimination diets supervised by the nutritionist. Main new therapeutic strategies for FA include allergen-specific (oral, sublingual, epicutaneous, subcutaneous immunotherapy and heat treatment of food) and nonallergen-specific therapies (humanized monoclonal antibodies, anti-IgE and anti-IL5, probiotics). An incorrect diagnosis is likely to result in unnecessary dietary restrictions, which, if prolonged, may adversely affect the child's nutritional status and growth.
\end{abstract}

Keywords Cow's milk allergy · Probiotics ·

Skin prick test - Atopy patch test - Oral food challenge . Elimination diet

\section{Introduction}

Food allergy (FA) is a major health issue in western societies affecting between 5 and $10 \%$ of young children [1]. During the last decade in the United States pediatric FA diagnosis rates increased by $18 \%$, however it has not been determined whether these findings are related to increased awareness and reporting. In any case, the use of specific medical diagnostic codes for FA does represent a real increase of the disease [2]. It has been estimated that FA, in the United States alone, accounts for 30,000 emergency room visits and 150 deaths per year [3]. In Italy, the
R. Berni Canani $(\bowtie) \cdot$ R. Nocerino $\cdot$ V. Pezzella $\cdot$ L. Leone .

T. Cozzolino · R. Aitoro - L. Paparo · M. Di Costanzo ·

L. Cosenza $\cdot$ R. Troncone

Food Allergy Unit, Department of Translational Medicine, University of Naples "Federico II", Via S. Pansini, 5,

80131 Naples, Italy

e-mail: berni@unina.it

R. Nocerino

e-mail: ritanocerino@alice.it

V. Pezzella

e-mail: cinzia.pezzella@gmail.com

L. Leone

e-mail: ludovicaleone@hotmail.it

T. Cozzolino

e-mail: tom.cozzolino@gmail.com

\author{
R. Aitoro \\ e-mail: aitoro.rosita@libero.it \\ L. Paparo \\ e-mail: lorella.paparo@alice.it \\ M. Di Costanzo \\ e-mail: mara.dicostanzo@live.it \\ L. Cosenza \\ e-mail: lindacosenza@libero.it \\ R. Troncone \\ e-mail: troncone@unina.it \\ R. Berni Canani · R. Troncone \\ European Laboratory for the Investigation of Food Induced \\ Diseases, University of Naples "Federico II", Via S. Pansini, 5, \\ 80131 Naples, Italy
}


number of hospital admissions due to food-induced anaphylaxis doubled in the last 5 years [4].

Although any food can provoke a reaction, relatively few foods are responsible for the vast majority of significant food-induced allergic reactions in children: cow's milk, hen's egg, soy, wheat, peanuts, tree nuts, fish and shellfish $[2,5]$. Allergy to other foods is increasing too, as exemplified by reports on sesame and kiwi [6]. There is also an increasing appreciation of oral allergy syndrome in children: patients with birch pollen allergy have cross reactions to heat-labile proteins in various fruits and vegetables [7].

Correct diagnosis of FA is important to accurately establish the prevalence and incidence of this condition and to ensure appropriate patient care. In fact, FA may have deleterious effects on family economics, social interactions, school and work attendance, and health-related quality of life. The diagnostic work-up in a child with FA includes many steps, but the essential criteria are a thorough medical history-taking and physical examination together with a clear response to the oral food challenge (OFC) $[8 \bullet]$.

\section{The Multistep Diagnostic Process}

Food allergies can be broadly divided into IgE (type I hypersensitivity)- and non-IgE (usually type IV hypersensitivity)-mediated diseases; or mixed, involving other immunoglobulins, immune complexes and/or cell-mediated mechanisms. These differ in clinical presentation, diagnostic testing, and prognosis [8 ${ }^{\bullet}$. IgE-mediated reactions are characterized by an acute onset of symptoms generally within $2 \mathrm{~h}$ after ingestion of or exposure to food. IgE-mediated reactions to food typically involve the skin, gastrointestinal tract, and respiratory tract and may include systemic reactions (anaphylactic shock). Non-IgE-mediated immunological reactions (e.g., cell-mediated) include food-protein-induced enterocolitis, proctocolitis, and enteropathy syndromes. These conditions primarily affect infants or young children who present with abdominal complaints, such as vomiting, abdominal cramps, diarrhea, and occasionally blood in the stool and failure to thrive or poor weight gain. Examples of FA co-morbidities with mixed IgE- and non-IgE-mediated causes include eosinophilic gastrointestinal diseases and atopic dermatitis [9]. Table 1 summarizes the main food-induced allergic disorders.

Adverse reactions to food that are not classified as FA include host-specific metabolic disorders (e.g., lactose intolerance), a response to a pharmacologically active component (e.g. an adverse reaction triggered by tyramine in aged cheeses), or toxins (e.g., food poisoning). Additionally, psychological (food aversion and anorexia nervosa) or neurologic (e.g., gustatory rhinorrhea from hot or spicy foods) responses can mimic FA [10•].

Food allergens may be split into two major classes: class 1 , the major food allergens, and class 2 , the indirect food allergens. Class 1 allergens comprise the classical food allergens to which patients become sensitized by the oral route or, possibly, through the skin. For these allergens, there is a clear association between ingestion (or contact) with the food and the onset of symptoms. Usually the allergens are heat stable; therefore both uncooked and cooked foods are problematic. Frequently, more than one organ system is involved. The primary allergens are highly conserved proteins or carbohydrates present within the pollen and fruits of a wide variety of plants. They include pathogenesis-related proteins (PRP), profilins, cross-reactive carbohydrate determinants (CCD) and lipid transfer proteins (LTP). Class 2 allergens comprise mainly pollen-derived allergens with cross-reactivity to foods and are often associated with oral allergy syndrome, sometimes called pollen-FA syndrome. Most commonly, sensitization is through the respiratory tract following pollen inhalation. Because class 2 allergens are usually heat labile and destroyed in the gastrointestinal tract, symptoms immediately follow eating raw fruit or vegetables. Examples of class 2 food allergens are latex, kiwi, apple, peach, hazelnut $\left[10^{\bullet}, 11^{\bullet}\right]$.

The evaluation of a child with suspected FA includes: indepth patient history, physical examination, screening tests, response to elimination diet and to OFC (Fig. 1). In children with multiple FAs, the response to elimination of single antigens is incomplete, and lengthy assessment with a very restricted diet is often required. The physician should obtain a detailed patient history focused on the kind and intake of symptom-inducing food, the time gap between food ingestion and onset of symptoms, reproducibility, presence or absence of any other symptom-inducing conditions, and the time of the last symptom. Timing of the first and last occurrences can reveal whether sensitivity is increasing or waning. An evaluation of possible cross reactions is helpful in selected cases. These considerations together with the quantity necessary to trigger a reaction are helpful for planning the best procedures to explore the presence of sensitization to particular foods and to perform OFC as well. Occasionally, the history can be complicated by the fact that trace amounts of foods may occur in certain products. The differential diagnosis could be particularly difficult in subjects with non-IgE-mediated FA where symptoms occur hours or days later. In addition, in a child with gastrointestinal symptoms, the differential diagnosis must also include: infections, gastrointestinal functional disorders, celiac disease, brush border enzyme deficiencies, cystic fibrosis and other primitive forms of pancreatic insufficiency, inflammatory bowel diseases, anatomical defects (e.g., pyloric stenosis, malrotation), metabolic disorders 
Table 1 Main food-induced allergic disorders

\begin{tabular}{|c|c|c|c|}
\hline & $\begin{array}{l}\text { IgE-mediated/acute onset } \\
\text { (onset time } 30 \mathrm{~min} \text { up to } 2 \mathrm{~h} \text { ) }\end{array}$ & $\begin{array}{l}\text { Non-IgE mediated/delayed onset (onset time } \\
\text { few hours to days) }\end{array}$ & $\begin{array}{l}\text { IgE- or non-IgE mediated/ } \\
\text { delayed onset (onset time } \\
\text { few hours to days) }\end{array}$ \\
\hline Gastrointestinal tract & $\begin{array}{l}\text { Oral allergy syndrome; } \\
\text { gastrointestinal anaphylaxis }\end{array}$ & $\begin{array}{l}\text { Dietary protein proctitis, colitis, enterocolitis, } \\
\text { enteropathy; gastroesophageal reflux } \\
\text { disease; food-protein-induced enterocolitis } \\
\text { syndrome; chronic constipation }\end{array}$ & $\begin{array}{l}\text { Eosinophilic esophagitis, } \\
\text { gastroenteropathies }\end{array}$ \\
\hline Respiratory tract & Rhinitis; conjunctivitis; asthma & $\begin{array}{l}\text { Chronic pulmonary disease (Heiner } \\
\text { syndrome) }\end{array}$ & Asthma \\
\hline Skin & Urticaria; angioedema & Contact dermatitis & Atopic dermatitis \\
\hline Systemic & $\begin{array}{l}\text { Anaphylaxis; food-associated, } \\
\text { exercise-induced anaphylaxis }\end{array}$ & - & - \\
\hline
\end{tabular}

Fig. 1 The diagnostic algorithm for food allergy. $S P T$ skin prick test, $A P T$ atopy patch test, $E C P$ eosinophilic cationic protein, $C L P$ fecal calprotectin, $F A$ food allergy. *Tissue damage markers and GI motility investigations could be used in patients with gastrointestinal sings and symptoms possibly related to $\mathrm{FA}$

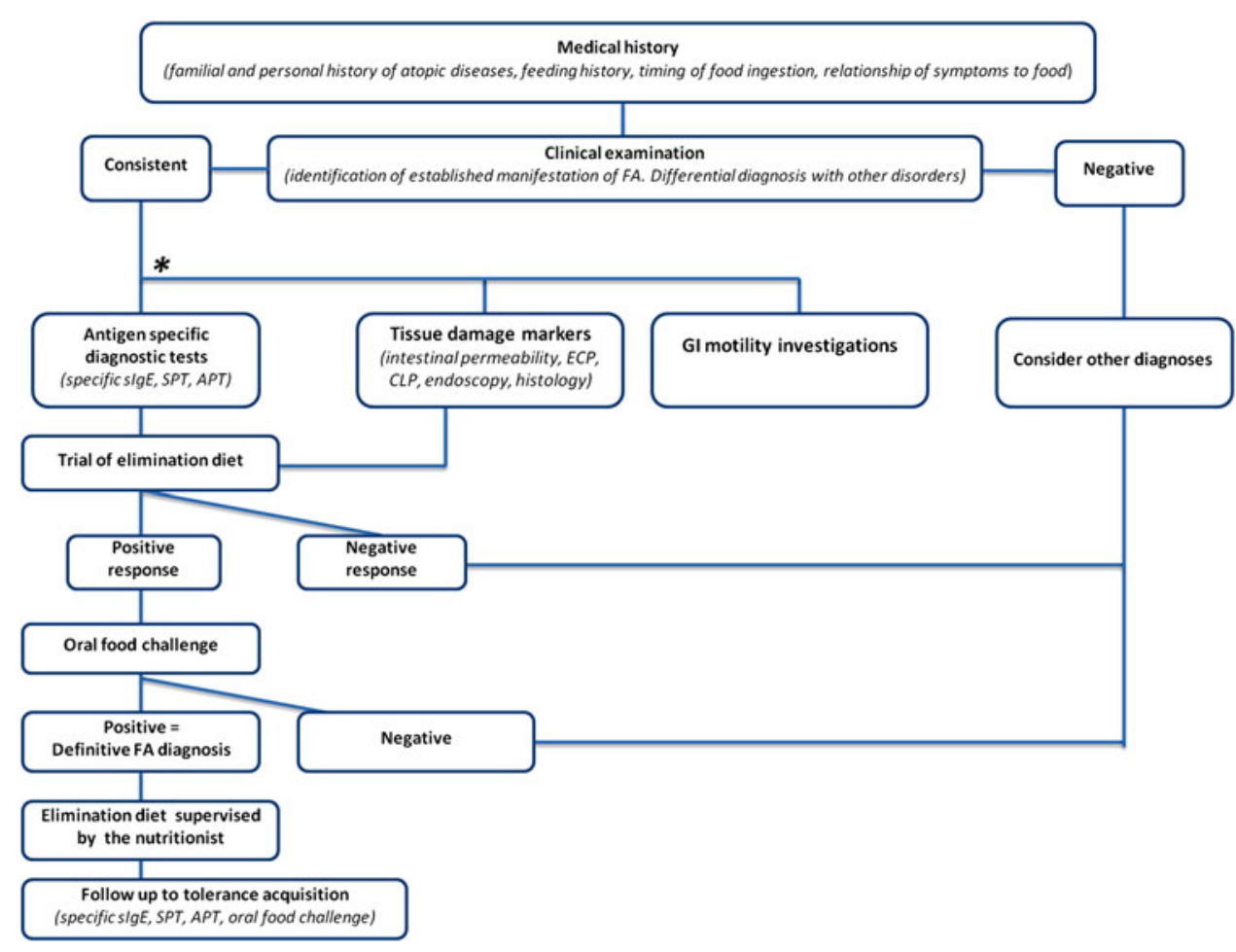

(e.g., galactosemia), adverse reaction to drugs, and Munchausen syndrome/Munchausen syndrome by proxy.

\section{Antigen-Specific Diagnostic Tests}

\section{In Vitro Tests}

In vitro tests (determining serum-specific $\operatorname{IgE}$ antibodies against food allergens) are commonly used in the diagnostic workup of FA, especially in patients with severe atopic dermatitis or patients taking antihistamines, where skin tests are not suitable. Serum IgE levels can be assessed for crude allergen extracts, individual allergens, or even allergenic peptides. The results can be a simple qualitative measurement resulting in a yes or no answer for the presence of food-specific IgE or alternatively they may determine a quantitative antibody level [12•]. Measurement of allergen-specific $\mathrm{IgE}$ is performed using the radioallergosorbent test; the detection limit of the system usually is $0.35 \mathrm{kU} / \mathrm{L}$ IgE. A subject is considered sensitized if their specific IgE levels exceed the detection limit. Many clinical studies have been performed to evaluate the reliability of in vitro testing for food-specific $\operatorname{IgE}$ to clinical FA. Using the ImmunoCAP system, threshold levels of allergen-specific IgE to egg $(6 \mathrm{kUa} / \mathrm{L})$, peanut $(15 \mathrm{kUa} / \mathrm{L})$, fish $(20 \mathrm{kUa} / \mathrm{L})$, and milk $(32 \mathrm{kUa} / \mathrm{L})$ have been shown to portend positive OFC results with greater than $95 \%$ accuracy [13•]. Therefore, evaluation of allergen-specific IgE could possibly obviate the need for potentially lifethreatening reactions to foods during challenge tests. There 
is emerging evidence that component-resolved diagnosis through measurement of specific IgE to individual, most often recombinant, food allergens may be superior to measurements of specific IgE to crude allergen extracts. For example, clinically relevant peanut allergy seems to correlate with the detection of specific IgE antibodies to Ara $\mathrm{h}$ 2, a seed storage protein in peanuts [14]. Homolog seed storage proteins also exist in tree nuts and seeds. In hazelnut allergies, detection of specific $\operatorname{IgE}$ to Cor a 9 suggests a FA that might result in a life-threatening reaction, whereas detection of specific IgE solely to Cor a 1, the homolog of the birch pollen allergen Bet $\mathrm{v}$ 1, suggests a pollen-associated FA [15]. Similarly, positive specific IgE to the LTP of hazelnut, Cor a 8, suggests an increased risk of severe systemic reactions. Similar improvement of the test performance and diagnostic sensitivity has been seen when using single kiwifruit allergens compared with the extract [16].

In IgE-mediated FA, circulating antibodies recognize specific molecular regions on the antigen surface (epitopes), which are classified according to their specific amino acid sequence (sequential or linear epitopes) or the folding and configuration of their protein chains (conformational epitopes). Subjects with transient FA produce IgE antibodies primarily directed at conformational epitopes (dependent on the protein's tertiary structure), whereas those with persistent FA also produce IgE antibodies against sequential epitopes, which are heat stable [17]. Greater $\operatorname{IgE}$ epitope diversity and higher IgE affinity are associated with more severe FA [18]. In the future, IgE epitope mapping has the potential to become an additional tool for the diagnosis/prognosis of FA and lead to a better understanding of the pathogenesis and tolerance induction [19].

Some cellular tests, i.e. tests determining the reactivity of blood cells in vitro (e.g., determination of histamine release, basophil degranulation, CAST-determination of sulfidoleukotrienes produced by IL-3 primed basophils stimulated by allergens in vitro- and flow cytometric basophil activation test), are increasingly used in selected tertiary centers with the aim to accurately define their diagnostic accuracy and standardization. Complementary/ alternative tests (e.g. ALCAT-test, bioresonance, kinesiology, leukocytotoxic test, electrodermal tests, iridology and hair analysis) are quite popular in clinical practice, but there is absolutely no evidence of their diagnostic value $[20,21]$.

\section{In Vivo Tests}

Immediate hypersensitivity skin prick tests (SPTs) examine for the presence of food protein specific IgE. SPTs usually have sufficient sensitivity and specificity to be the sole method of skin testing necessary for most clinical scenarios. In general, SPTs have a sensitivity of $\sim 90 \%$ but a specificity of only about $50 \%$ [22]. An important component of management is the understanding by clinicians of the predictive value of individual FA tests. The larger the size of the wheal on a skin test, the more likely a patient will react to the food (Table 2) [12, 22, 23]. The quality and allergen content of the extract employed for the test are pivotal. Thus, patients with oral allergy syndrome induced by fresh, but not cooked, tree fruit associated with tree pollen allergy usually do not show positive tests to commercial extracts. Some studies reported that the SPTs are positive $40 \%$ of the time with commercial extracts and $81 \%$ of the time using fresh foods. The overall concordance between a positive prick test and a positive challenge test is $59 \%$ with commercial extracts and $92 \%$ when fresh foods were used [24]. When a history is positive, and a commercial food antigen SPT is negative, a prick using fresh food should be considered.

For non-IgE-mediated disorders, fewer diagnostic tools exist. Atopy patch tests (APTs) are able to explore cellmediate reactions, and they are the most used FA screening tests in the clinical practice. There is no minimum age for these tests, which can be performed also in preterm babies and infants with useful results $[9,25]$. APTs have been proposed for the initial diagnostic approach in children with suspected non-IgE-mediated CMA and atopic dermatitis [26], gastrointestinal disorders [26-28] and eosinophilic esophagitis [27]. The use of APTs in the clinical practice of pediatric gastroenterology could be limited by subjective interpretation and intra-observer variation. Recently it has been demonstrated that in children with gastrointestinal symptoms the diagnostic accuracy of APTs is influenced by the severity of skin signs [29] and that APTs could be a valuable tool in the follow-up of pediatric patients with gastrointestinal symptoms related to non-IgEmediated cow's milk allergy by contributing to the determination of whether an OFC can safely be undertaken [30].

Table 2 Diagnosis of food allergy with the use of $95 \%$ positive predictive value (PPV) for specific IgE and skin prick tests

\begin{tabular}{|c|c|c|}
\hline & $\begin{array}{l}\text { Serum-specific } \operatorname{IgE} \\
(\mathrm{U} / \mathrm{mL})\end{array}$ & $\begin{array}{l}\text { Skin prick test wheal } \\
\text { diameter }(\mathrm{mm})\end{array}$ \\
\hline Cow's milk & $\begin{array}{l}15 \text { ( } 5 \text { if the child age is } \\
<2 \text { years) }\end{array}$ & $\begin{array}{l}8 \text { ( } 6 \text { if the child age is } \\
<2 \text { years) }\end{array}$ \\
\hline Hen's egg & $\begin{array}{l}7 \text { ( } 2 \text { if the child age is } \\
<2 \text { years) }\end{array}$ & $\begin{array}{l}7 \text { ( } 5 \text { if the child age is } \\
<2 \text { years) }\end{array}$ \\
\hline Fish & 20 & 7 \\
\hline Peanuts & 15 & $\begin{array}{l}8 \text { ( } 4 \text { if the child age is } \\
<2 \text { years) }\end{array}$ \\
\hline
\end{tabular}


Tissue Damage Markers and Gastrointestinal Motility Investigations

Several procedures could be adopted in children with gastrointestinal symptoms possibly related to FA. These include endoscopy with histologic evaluation, esophageal $\mathrm{pH}$ monitoring; together with noninvasive tissue damage markers, such as intestinal permeability, faecal eosinophilic cationic protein and calprotectin measurement $[8,31]$. Although these noninvasive tests would be convenient to detect an intestinal mucosal reaction to foods, no conclusive studies are available on the diagnostic accuracy of these tests, alone or in combination, in the approach to a child with suspected FA. Patients with allergic eosinophilic esophagitis or gastroenteritis have peripheral eosinophilia, and children with severe allergic eosinophilic gastroenteritis might have anaemia, blood in the stool and decreased serum albumin and $\operatorname{IgG}$ levels. Endoscopy with biopsies are the most definitive approach and might help in the differential diagnosis. Density $>15$ eosinophils/HPF in the oesophagus is diagnostic for allergic eosinophilic esophagitis, especially if the oesophageal $\mathrm{pH}$ monitoring is normal and there is lack of response to high-dose proton pump inhibitors medication [26]. If food-induced enteropathy or colitis are suspected, intestinal biopsies revealing primarily eosinophilic infiltration of the mucosa may be helpful. The mucosal lesions in FA enteropathies are characteristically focal. Thus, sampling error may result in negative biopsies in a discrete number of cases. Colonic biopsies are more often helpful in cases with allergic colitis, usually seen in infants with FAinduced hematochezia. In children with FA, electrogastrographic evidence of severe gastric dysrythmia and delayed gastric emptying during OFC have been demonstrated. The investigations on FA-related motility disorders could be performed by multichannel intraluminal electrical impedance testing, micromanometric techniques, gastroelectrophysiological studies, or measurement of gastric emptying by ${ }^{13} \mathrm{C}$-octanoic acid breath test [32].

\section{Oral Food Challenge}

Oral food challenge still represents the gold standard for the diagnosis of FA in order to avoid unjustified diets. When the food considered for the challenge is still part of the patient's diet, a strict elimination diet should be prescribed for at least 2 weeks before the OFC. The optimal duration of elimination diet before OFC depends mainly on symptom severity. Different FA-related gastrointestinal diseases need different durations of elimination diet before OFC: an elimination of 4-6 weeks is considered adequate for enterocolitis, proctitis/proctocolitis and enteropathy. However, for gastroesophageal reflux disease and constipation, just 2-4 weeks are adequate. The OFC is done by feeding gradually increasing amounts of the suspected food under observation by a physician over a period of hours, protracted for days when no immediate reaction occurs. Because the procedure carries a small risk of anaphylaxis, it should be conducted in a supervised medical setting where resuscitation equipment is available. Several papers have been published recently on this topic aiming at standardizing the procedure [33-35]. The main problems of OFC are related to the wide variety of symptoms possibly related to immunological mechanism of FA that lead to difficulties in the interpretation of results and to the optimal timing and dosage of this procedure. A rather complex, double-blindplacebo-controlled food challenge (DBPCFC), routinely used in research, is recommended in clinical settings only when patients report entirely subjective symptoms; whereas an open OFC without placebo is commonly used in children under the age of 3 years and when objective symptoms are present [36-38]. Unfortunately, the diagnosis of FA is frequently incomplete, incorrect, or self-reported, and a correct diagnostic work-up, confirmed by OFC, seems to be adopted in only a minority of cases [39].

\section{Therapeutic Options}

\section{Elimination Diet}

Although numerous therapeutic treatment options are currently being investigated, dietary avoidance remains the primary treatment for FA [40*]. Inadequate nutritional status, growth, and dietary intakes have been demonstrated in children with FA [41]. Altered growth status may be due to potential loss of nutrients caused by continued allergic inflammation and/or abnormal intestinal permeability caused by noncompliance with the diet, unbalanced diet and additional undiagnosed FA or inappropriate substitute foods [41]. This highlights the need to make every effort to optimize nutrition because inadequate nutrient intake may worsen the risk of lower growth rates in this population. The elimination diet should be considered carefully depending on: mechanism of FA; symptoms; nutritional status; and concomitant factors like food aversive behavior. A properly managed, well-balanced elimination diet prescribed with the help of certified dietitians, can lead to resolution of symptoms while maintaining or even optimizing nutritional status.

Critical points in the management of the patient are the protein:energy ratio and the energy requirements. In fact, the rate of catch-up growth required (based on the weight for height or S.D. scores) depends on the individual patients' current nutritional status, and allergen restrictions. The ideal protein:energy ratio lies between 8.9 and $11.5 \%$ of total energy; this ratio could be further increased depending on 
the level of stunting. In addition, for optimal catch-up growth, $5-10 \mathrm{~g} / \mathrm{kg} /$ day of protein and $105-126 \mathrm{kcal} / \mathrm{kg} / \mathrm{day}$ are commonly required [42].

An often neglected component of treatment is to ensure patients and/or their caregivers understand the importance of complete adherence to the diet, as inadvertent consumption of an offending food can prevent resolution of symptoms and render challenge results useless. As many FAs of early childhood resolve over time, regular reassessment by the allergist is also important to avoid extended, unnecessary elimination diets.

Even under the best circumstances, avoidance of allergens is not simple. The variety of commercial food items available is ever expanding, and ingredients in commercial products change frequently, requiring consumers to read product labels each and every time an item is purchased. Laws that guide the labeling of food allergens vary from country to country [43]. These laws typically require identification and disclosure on product labels of those food components that are considered 'common food allergens' or 'major allergens'. Healthcare practitioners and consumers should be aware of their country's food allergen labeling laws. When traveling abroad, consumers with FA should always check the food allergen labeling laws of their destination country prior to purchasing and consuming packaged foods [44].

\section{Immunotherapy}

The main new therapeutic perspectives for the treatment of FA include allergen-specific (oral, sublingual, epicutaneous, subcutaneous immunotherapy (SCIT) and heat treatment of food) and non-allergen-specific therapies (humanized monoclonal antibodies, anti-IgE and anti-IL5, probiotics). Oral food immunotherapy (OIT) is currently the most investigated approach for persistent FA. This method is based on the concept that repeated oral/intestinal exposures to antigens normally lead to tolerance. OIT protocols usually provide an initial stage with progressive increase of the dose, followed by a phase of slow accumulation to achieve the desired maintenance dose. Several studies have demonstrated that OIT with milk is effective in desensitizing patients with cow's milk allergy [45, 46]. The aim of the experimental studies of OIT is to develop a safe protocol that can be used in routine clinical practice. There is still controversy on OIT, due to concerns for heterogeneity in protocols, compliance of patients and their families, failure of desensitization and presence of atopic disease. Moreover, patients with complicated IgE- and non-IgE-mediated disease may not respond well to OIT. In sublingual immunotherapy (SLIT) the food is administered sublingually, held in the mouth for few minutes, and then spat or swallowed. Several studies with hazelnut, milk, peanut, and peach have demonstrated the benefit of SLIT in increasing the amount of the food tolerated on DBPCFC [47-49]. Side effects are generally mild, mainly limited to oropharyngeal symptoms, and rarely require oral antihistamine administration. However, the maximum dose that can be administered sublingually is limited, which may limit the maximum dose of food that can be ultimately tolerated [50•]. Further studies are needed to standardize the method and demonstrate its safety in larger numbers of patients. The use of SCIT in persistent FA was quickly discontinued after reports of fatal reactions with peanut injections. Consequently, this approach is no longer used [50•]. In epicutaneous immunotherapy (EIT), patients receive three 48-h skin patch applications (1 mg of skimmed milk powder) per week for 3 months [51•]. Adverse effects are mostly local cutaneous reactions and discomfort (pruritis and eczema), but don't include any severe systemic reactions. While EIT appears safe, additional studies are required to examine efficacy in terms of additional foods, and what are the maximum doses that can be applied epicutaneously and tolerated orally [50 ${ }^{\circ}$. Omalizumab is a recombinant humanized monoclonal IgE-blocking antibody. It's an allergen non-specific modality of FA treatment. It decreases or prevents the allergic response triggered by $\operatorname{IgE}$ molecules, binding to the constant domains of free circulating IgE molecules, reducing IgEmediated mast cell and basophil degranulation on allergen exposure [52•, 53]. Subcutaneous injections of omalizumab have been shown to have relatively few and tolerable side effects mainly at the injection site. Less common reactions included bronchospasm, hypotension, syncope, urticaria, angioedema and rarely anaphylaxis $[54,55]$. Other therapeutic strategies with modified allergens (peptides, sequences of oligodeoxynucleotides, plasmid DNA) have been evaluated in preclinical studies for the possible treatment of peanut allergy, but they are currently underutilized. It is possible that in the future such studies can be resumed as a result of a better characterization of antigenic epitopes responsible for the various forms of FAs.

\section{New Therapeutic Perspectives Deriving}

from Immunonutrition

"Immunonutrition", a diet-induced immunomodulation, is becoming an increasingly realistic therapeutic option for FA. The more promising strategies involve modified antigenic peptides and probiotics. Heating cow's milk and hen's egg decreases protein allergenicity by destroying conformational epitopes. The introduction of extensively heated milk and egg protein in the diet of subjects with milk and egg allergy, who tolerate the baked form, is becoming an alternative approach to induce a faster acquisition of oral tolerance. Children who incorporated 
baked milk or baked egg into the diet are 16 and 14.6 times more likely to become tolerant to unheated milk and egg compared with a comparison group of children who continued strict avoidance of these foods $[56 \bullet, 57 \bullet]$.

Recent data strongly suggest that gut microbiota is important for oral tolerance development [58 $]$. Administration of the probiotic Lactobacillus rhamnosus GG (LGG) to food-allergic children (age $<2$ years, challenge-proven and affected by mild-to-moderate eczema) improved the eczema score significantly [58•]. Studies in infants with eczema who received formulas supplemented with LGG showed benefits in decreasing gastrointestinal symptoms [59]. For instance, after a challenge study in infants allergic to cow's milk proteins, fecal IgA levels were detected to be higher, and TNF- $\alpha$ levels were lower in the LGG applied group compared to the placebo [58•]. Nermes et al. [60] showed a significant decrease in IgA- and IgM-secreting cells in infants with atopic dermatitis treated with extensively hydrolyzed casein formula (eHCF) supplemented with LGG, suggesting that this particular probiotic is able to enhance gut barrier function and accelerate immunological maturation in infants with FA. Moreover, LGG is able to induce IFN- $\gamma$ secretion in infants with CMA and in infants with IgE-associated dermatitis, but not in infants without CMA [58]. The addition of LGG to an eHCF significantly improved the recovery of the inflamed colonic mucosa if compared to that obtained with eHCF alone in infants with blood in the stool and CMA-induced colitis, as indicated indirectly by greater decrease in fecal calprotectin and in the number of infants with persistence of occult blood in stools after 1 month [61]. We recently demonstrated that an eHCF containing LGG is able to accelerate the development of tolerance acquisition in infants with CMA. Infants (aged 1-12 months), consecutively referred for suspected CMA but still receiving cow's milk proteins, were invited to participate in the study. Subjects were randomly allocated to one of the two groups of dietary interventions: a control group, who received an eHCF; and an active group, who received an eHCF containing LGG (at least $1.4 \times 10^{7} \mathrm{CFU} /$ $100 \mathrm{~mL}$ ). After 12 months, the DBPCFC was negative in 15 of 28 control infants $(53.6 \%)$ and in 22 of 27 infants receiving eHCF with $\mathrm{LGG}(81.5 \%, p=0.027)$. These findings suggest an innovative approach for infants affected by CMA, namely an "active dietotherapy" able to induce a faster symptom's remission and to reduce the time of tolerance acquisition [62•].

\section{Conclusions}

Correct diagnosis of FA is crucial to ensure appropriate patient care. The essential criterion is a clear response to elimination diet, and other diagnostic tests are secondary to this. OFC plays a crucial role in the diagnostic approach to a child with suspected FA, but it is largely underutilized. Potential responsible factors contributing to the lack of a correct diagnostic work-up in the vast majority of cases could be numerous, and include lack of training on the procedure, increased reliability on screening methods, extensive time needed, fear of risk, and suboptimal fee reimbursement. A comprehensive nutrition assessment with appropriate intervention is warranted in all children with FAs to meet nutrient needs and optimize growth. Frequently an elimination diet is absolutely necessary to prevent potentially life-threatening food allergic reactions. However, dietary elimination in FA may also have undesirable consequences. An increasing number of evidences suggest the role of selected probiotics in prevention or treatment of FA. These data support the importance of a "nutritional immunology approach" able not only to efficiently cure the symptoms, but also to accelerate tolerance acquisition in children with FA.

Disclosure Roberto Berni Canani, Rita Nocerino, Vincenza Pezzella, Ludovica Leone, Tommaso Cozzolino, Rosita Aitoro, Lorella Paparo, Margherita Di Costanzo, Linda Cosenza, and Riccardo Troncone declare that they have no conflict of interest.

Human and Animal Rights and Informed Consent This article does not contain any studies with human or animal subjects performed by any of the authors.

\section{References}

Papers of particular interest, published recently, have been highlighted as:

- Of importance

1. Kuehn BM. Food allergies becoming more common. JAMA. 2008;300:2358.

2. Bush RK. Approach to patients with symptoms of food allergy. Am J Med. 2008;121:376-8.

3. The Food Allergy \& Anaphylaxis Network. Food Allergy Training Guide for Hospital and Food Service Staff. FAAN. http://foodallergy.org. Accessed 24 June 2006.

4. Berni Canani R, Nocerino R, Terrin G, et al. Hospital admissions for food-induced anaphylaxis in Italian children. Clin Exp Allergy. 2012;42:1813-4.

5. Ramesh S. Food allergy. Overview in children. Clin Rev Allerg Immunol. 2008;34:217-30.

6. Dias RP, Summerfield A, Khakoo GA. Food hypersensitivity among Caucasian and non-Caucasian children. Pediatr Allergy Immunol. 2008;19:86-9.

7. Bohle B. The impact of pollen-related food allergens on pollen allergy. Allergy. 2007;62:3-10 Review.

8. - Ho MH, Wong WH, Chang C. Clinical spectrum of food allergies: a comprehensive review. Clin Rev Allergy Immunol. 2012 Nov 16 (in press). Comprehensive review for food allergy.

9. Berni Canani R, Ruotolo S, Discepolo V, et al. The diagnosis of food allergy in children. Curr Opin Pediatr. 2008;20:584-9. 
10. - Burks AW, Tang M, Sicherer S, et al. ICON: food allergy. J Allergy Clin Immunol. 2012;129:906-20. Comprehensive review for food allergy.

11. - Sicherer SH, Sampson HA. Food allergy. J Allergy Clin Immunol 2010;125:S116-125. Comprehensive review for food allergy.

12. - Eigenmann PA, Oh JW, Beyer K. Diagnostic testing in the evaluation of food allergy. Pediatr Clin North Am. 2011;58:35162. Comprehensive review for the diagnosis of food allergy.

13. - Hamilton RG. Clinical laboratory assessment of immediate type hypersensitivity. J Allergy Clin Immunol 2010;125:S284-296. Comprehensive review for the diagnosis of food allergy.

14. Nicolaou N, Poorafshar M, Murray C, et al. Allergy or tolerance in children sensitized to peanut: prevalence and differentiation using component-resolved diagnostics. J Allergy Clin Immunol. 2010;125:191-7.

15. Schocker F, Luttkopf D, Scheurer S, et al. Recombinant lipid transfer protein Cor a 8 from hazelnut: a new tool for in vitro diagnosis of potentially severe hazelnut allergy. J Allergy Clin Immunol. 2004;113:141-7.

16. Bublin M, Pfister M, Radauer C, et al. Component-resolved diagnosis of kiwifruit allergy with purified natural and recombinant kiwifruit allergens. J Allergy Clin Immunol. 2010;125: 687-94.

17. Fiocchi A, Bouygue GR, Albarini M, et al. Molecular diagnosis of cow's milk allergy. Curr Opin Allergy Clin Immunol. 2011; 11:216-21 Review.

18. Wang J, Lin J, Bardina L, et al. Correlation of IgE/IgG4 milk epitopes and affinity of milk-specific IgE antibodies with different phenotypes of clinical milk allergy. J Allergy Clin Immunol. 2010;125:695-702.

19. Jing Lin J, Sampson HA. The role of immunoglobulin E-binding epitopes in the characterization of food allergy. Curr Opin Allergy Clin Immunol. 2009;9:357-63.

20. Robinson M, Smart J. Allergy testing and referral in children. Aust Fam Physician. 2008;37:210-3.

21. Boyce JA, Assa'ad A, Burks AW, et al. Guidelines for the diagnosis and management of food allergy in the United States: report of the NIAID-sponsored expert panel. J Allergy Clin Immunol. 2010;126(6 Suppl):S1-58.

22. Eigenmann PA, Calza AM. Diagnosis of IgE-mediated food allergy among Swiss children with atopic dermatitis. Pediatr Allergy Immunol. 2000;11:95-100.

23. Spergel JM, Beausoleil JL, Fiedler JM, et al. Correlation of initial food reactions to observed reactions on challenges. Ann Allergy Asthma Immunol. 2004;92:217-24.

24. Joint Task Force on Practice Parameters. Allergy diagnostic testing: an updated practice parameter. Ann Allergy Asthma Immunol. 2008;100:S1-148.

25. Dupont C, Soulaines P, Lapillonne A, et al. Atopy patch test for early diagnosis of cow's milk allergy in preterm infants. J Pediatr Gastroenterol Nutr. 2010;50:463-4.

26. Furuta GT, Liacouras CA, Collins MH, et al. First International Gastrointestinal Eosinophilic Research Symposium (FIGERS) Subcommittees. Eosinophilic esophagitis in children and adults: a systematic review and consensus recommendations for diagnosis and treatment. Gastroenterology. 2007;133:1342-63.

27. Fogg MI, Brown-Whitehorn TA, Pawlowski NA, et al. Atopy patch test for the diagnosis of food protein-induced enterocolitis syndrome. Pediatr Allergy Immunol. 2006;17:351-5.

28. Berni Canani R, Ruotolo S, Auricchio L, et al. Diagnostic accuracy of the atopy patch test in children with food allergyrelated gastrointestinal symptoms. Allergy. 2007;62:738-43.

29. Berni Canani R, Nocerino R, et al. Toward a standardized reading of the atopy patch test in children with suspected cow's milk allergy-related gastrointestinal symptoms. Allergy. 2011;66: 1499-500.

30. Nocerino R, Granata V, Di Costanzo M, et al. Atopy patch tests are useful to predict oral tolerance in children with gastrointestinal symptoms related to non-IgE-mediated cow's milk allergy. Allergy. 2013;68:246-8.

31. Mansueto P, Montalto G, Pacor ML, et al. Food allergy in gastroenterologic diseases: review of literature. World J Gastroenterol. 2006;12:7744-52.

32. Heine RG. Gastroesophageal reflux disease, colic and constipation in infants with food allergy. Curr Opin Allergy Clin Immunol. 2006;6:220-5.

33. Ito K, Urisu A. Diagnosis of food allergy based on oral food challenge test. Allergol Int. 2009;58:467-74.

34. Nowak-Wegrzyn A, Assa'ad AH, Bahna SL. Work group report: oral food challenge testing. J Allergy Clin Immunol. 2009; 123:S365-83.

35. Niggemann B. When is an oral food challenge positive? Allergy. 2010;65:2-6.

36. Niggemann B, Beyer K. Pitfalls in double-blind, placebo-controlled oral food challenges. Allergy. 2007;62:729-32.

37. Venter C, Pereira B, Voigt K, et al. Comparison of open and double-blind placebo controlled food challenges in diagnosis of food hypersensitivity amongst children. J Hum Nutr Diet. 2007;20:565-79.

38. Bahana SL. Food challenge procedure: optimal choices for clinical practice. Allergy Asthma Proc. 2007;28:640-6.

39. Berni Canani R, Nocerino R, Terrin G, et al. Food allergy diagnostic practice in Italian children. J Allergy Clin Immunol. 2012;129:1423-4.

40. - Nowak-Wegrzyn A, Sampson HA. Future therapies for food allergies. J Allergy Clin Immunol 2011;127:558-73. Comprehensive review for the therapy of food allergy.

41. Flammarion S, Santos C, Guimber D, et al. Diet and nutritional status of children with food allergies. Pediatr Allergy Immunol. 2011;22:161-5.

42. Meyer R, Venter C, Fox A, et al. Practical dietary management of protein energy malnutrition in young children with cow's milk protein allergy. Pediatr Allergy Immunol. 2012;23:307-14.

43. Gendel SM. Comparison of international food allergen labeling regulations. Regul Toxicol Pharmacol. 2012;63:279-85.

44. National guidelines on management and labelling of allergens. http://www.foodallergens.info/Manufac/Guidelines html. Accessed December 2012.

45. Skripak JM, Nash SD, Rowley H, et al. A randomized, doubleblind, placebo-controlled study of milk oral immunotherapy for cow's milk allergy. J Allergy Clin Immunol. 2008;122:1154-60.

46. Longo G, Barbi E, Berti I, et al. Specific oral tolerance induction in children with very severe cow's milk-induced reactions. J Allergy Clin Immunol. 2008;121:343-7.

47. Enrique E, Malek T, Pineda F, et al. Sublingual immunotherapy for hazelnut food allergy: a follow-up study. Ann Allergy Asthma Immunol. 2008;100:283-4.

48. de Boissieu D, Dupont C. Sublingual immunotherapy for cow's milk protein allergy: a preliminary report. Allergy. 2006;61: 1238-9.

49. Kim EH, Bird JA, Kulis M, et al. Sublingual immunotherapy for peanut allergy: clinical and immunologic evidence of desensitization. J Allergy Clin Immunol. 2011;127:640-6.

50. - Khoriaty E, Umetsu DT. Oral immunotherapy for food allergy: towards a new horizon. Allergy Asthma Immunol Res. 2013;5:3-15. Comprehensive review for therapy of food allergy.

51. - Dupont C, Kalach N, Soulaines P, et al. Cow's milk epicutaneous immunotherapy in children: a pilot trial of safety, acceptability, and impact on allergic reactivity. J Allergy Clin Immunol. 
2010;125:1165-7. Comprehensive review for therapy of food allergy.

52. - Kopp MV. Omalizumab: Anti-IgE therapy in allergy. Curr Allergy Asthma Rep. 2011;11:101-6. Interesting paper focused on the therapy of food allergy.

53. Holgate S, Casale $\mathrm{T}$, Wenzel $\mathrm{S}$, et al. The anti-inflammatory effects of omalizumab confirm the central role of $\mathrm{IgE}$ in allergic inflammation. J Allergy Clin Immunol. 2005;115:459-65.

54. Holgate S, Smith N, Massanari M, et al. Effects of omalizumab on markers of inflammation in patients with allergic asthma. Allergy. 2009;64:1728-36 Review.

55. Kopp MV, Hamelmann E, Zielen S, et al. DUAL study group. Combination of omalizumab and specific immunotherapy is superior to immunotherapy in patients with seasonal allergic rhinoconjunctivitis and co-morbid seasonal allergic asthma. Clin Exp Allergy. 2009;39:271-9.

56. - Kim JS, Nowak-Wegrzyn A, Sicherer SH, et al. Dietary baked milk accelerates the resolution of cow's milk allergy in children. J Allergy Clin Immunol. 2011:128:125-31. Interesting article on new concept for tolerance acquisition.

57. - Leonard SA, Sampson HA, Sicherer SH, et al. Dietary baked egg accelerates resolution of egg allergy in children. J Allergy
Clin Immunol. 2012:130:473-80. Interesting article on new concept for tolerance acquisition.

58. - Berni Canani R, Di Costanzo M. Gut microbiota as potential therapeutic target for the treatment of cow's milk allergy. Nutrients. 2013;5:651-62. Comprehensive review on new concepts for the treatment of food allergy.

59. Isolauri E, Arvola T, Sutas Y, Moilanen E, et al. Probiotics in the management of atopic eczema. Clin Exp Allergy. 2000;30:1604-10.

60. Nermes M, Kantele JM, Atosuo TJ, et al. Interaction of orally administered Lactobacillus rhamnosus GG with skin and gut microbiota and humoral immunity in infants with atopic dermatitis. Clin Exp Allergy. 2010;41:370-7.

61. Baldassarre ME, Laforgia N, Fanelli M, et al. Lactobacillus GG improves recovery in infants with blood in the stools and presumptive allergic colitis compared with extensively hydrolyzed formula alone. J Pediatr. 2010;156:397-401.

62. - Berni Canani R, Nocerino R, Terrin G, et al. Effect of extensively hydrolyzed casein formula supplemented with Lactobacillus GG on tolerance acquisition in infants with cow's milk allergy: a randomized trial. J Allergy Clin Immun. 2012,129: 580-582. First clinical evidence on the potential utility of probiotic in oral tolerance induction in children with food allergy. 